\title{
Behaviorism and the biological viewpoint of personality
}

\author{
JOHN GORMLY \\ Rutgers University, New Brunswick, New Jersey 08903
}

\begin{abstract}
Thirty members of a fraternity were rated by each other to yield trait scores for energetic and sociable. The subjects also completed 14 days of records that described their locations and activities. It was predicted that energetic and sociable people would select experiences that were consistent with their personality traits. Using participation in sports as an example, there was a strong relationship $(R=.70)$ between personality traits and selection of experiences. It was suggested that this relationship was influenced by biologically based preferences for particular experiences and that random assignment to experimental conditions is a limited model for studying behavior. Approach-avoidance, the selection of experiences, is a core process of the person and is a class of behavior which is likely to be predictable from personality trait scores.
\end{abstract}

The trait viewpoint of personality holds that people have some consistent styles of behaving that are observable across a variety of settings. The degree of these consistencies in behavior can be described with scores along dimensions of aggressive, anxious, energetic, impulsive, sociable, and other such traits. The origins of individual differences in traits is of fundamental concern in psychology: How does it happen that one individual is highly sociable, for example, and another is hardly sociable at all?

The dominant philosophy of science currently influencing psychology is behaviorism, which emphasizes the role of experience or learning in determining behavior. Indeed, there is a substantial body of experimental evidence supporting the relationship between experience and behavior (Bandura, 1977), and one might conclude, then, that differences among people in traits are the result of differences in experiential histories.

On the other hand, however, are substantial data that demonstrate the high degree of heritability in trait scores, indicating that individual differences along trait dimensions are strongly influenced by genetic factors. This is true for personality syndromes like schizophrenia (Rosenthal, Wender, Kety, Welner, \& Schulsinger, 1971) and a wide variety of common traits (Buss, Plomin, \& Willerman, 1973; Dworkin, Burke, Maher, \& Gottesman, 1976).

Although learning theory and biological viewpoints are sometimes presented as competing explanations for behavior, they are more likely complementary. This appears to be so in the development of personality traits. One direction this complementary process might take is that, within the limits of their particular environments, people tend to select experiences that suit their biological dispositions. In this way, the selection of preferred experiences by individuals acts as an amplifier of differences that already exist. An aggressive boy joining a boxing team would be an example of this amplification process.

It is the purpose of this study to demonstrate that individuals do, in fact, select experiences in a manner that is consistent with their personality traits. The traits energetic and sociable are used in this study because they have substantial heritability values and because they are readily measurable.

\section{METHOD}

Subjects

The subjects for this study were 30 men who were members of a fraternity at a large Eastern state university. They were paid for their participation.

\section{Procedure}

The subjects came to the laboratory one at a time to complete personality ratings and to receive instructions. Each person was asked to rate himself and the other members of his fraternity as to whether they were "energetic-physically active" and "sociable-extraverted, socially outgoing," among other traits unrelated to this report. The instructions for the ratings were as follows: "If the trait is a characteristic of any of the people listed below, print YES before that person's name. If the trait is not a characteristic of the person, then print NO before his name. Each person should have either a YES or NO before his name." The person's trait score was the proportion of raters who said the trait name was characteristic of him. This procedure of peer descriptions and scoring has been shown to produce trait scores that are reliable and valid (Gormly \& Edelberg, 1974; McGowan \& Gormly, 1976).

When the subjects had completed the trait ratings, they were instructed to keep a log that was to contain the following information: (1) their location, (2) the time they entered that location, and (3) the activities they performed there. They were told to make an entry in the log for each time they changed locations. The logs were collected each day from the fraternity house. They were required to complete logs for 14 consecutive days. The event in the log that is relevant to this report was the number of times the men participated in sports. It was expected that participation in sports would be an experience that men living in college communities who were energetic and sociable 
would select for themselves, and participation in sports would be avoided by people who were not energetic and sociable. There was little or no external pressure on the men to participate in sports; yet is was a popular activity. There was considerable opportunity for participation. The gymnasium is on the same street as the fraternity house, and there is active interfraternity competition in a variety of sports.

\section{RESULTS}

Spearman's rank-order correlation statistic was used to estimate the strength of the relationships among the variables. Energetic scores were associated with number of times participated in sports $(\mathrm{r}=.63, \mathrm{p}<.01)$, and sociable scores were associated with number of times participated in sports $(\mathrm{r}=.52)$. The multiple correlation for energetic and sociable with participation in sports was $R=.70(\mathrm{p}<.01)$.

\section{DISCUSSION}

Personality traits are more than descriptions of regularities in behavior, they represent dynamic characteristic of the person, the selection of experiences. The magnitude of the relationships between trait scores and behavior in this study is large compared to those that are generally reported for personality scores (see Mischel, 1968, for a review). One reason for this is that the method of personality assessment used here, peer ratings from a large number of peers, results in a more valid assessment of personality characteristics than do self-report answers to a set of questions. Another reason for the strong association in the present study is the kind of behavior that is being measured, approach-avoidance (Gormly \& Gormly, 1981). Approachavoidance is such an important aspect of a person's behavior that it is likely to be a more stable behavior of the person than most other acts personality scores are used to predict.

Although psychology is currently focusing on the way that experience acts upon individuals, it is important to recognize that outside experiments, there is not random assignment of people to conditions. Individuals select their experiences in ways that are consistent with their personalities. Because the heritability coefficients for many personality characteristics are quite high, it is reasonable to infer that biological factors play a major role in determining preferences for experiences. Environmentalism (behaviorisms) must take into consideration the importance of biological influences in any attempt to have a robust theory of human behavior.

The selection of experiences is certainly not the only way that biological/trait dispositions influence experience. Cadoret, Cunningham, Loftus, and Edwards (1975) studied two groups of adopted children; all children were separated from their parents at birth. The biological parents of one group were classified as psychiatrically disturbed people, and the biological parents of the other group were normal. More than twice as many children whose biological parents were disturbed had been in treatment for behavioral disorders. Thus, aside from selecting experiences, people are likely to be assigned to experiences (particularly in childhood) in ways that are consistent with their biologically influenced personality characteristics.

People select experiences and are assigned to experiences in ways that are consistent with their personalities. This makes the experiment, with its procedure of random assignment to experimental conditions, a limited model for studying the behavior of people; the dynamic aspect of the person, selecting conditions, is an important but understudied variable.

\section{REFERENCES}

Bandura, A. Social learning theory. Englewood Cliffs, N.J: Prentice-Hall, 1977.

Buss, A. H., Plomin, R., \& Willerman, L. The inheritance of temperament. Journal of Personality, 1979, 41, 513-524.

Cadoret, R., Cunningham, L., Loftus, R., \& Edwards, J. Studies of adoptees from psychiatrically disturbed biologic parents. Journal of Pediatrics, 1975, 87, 301-306.

Dworkin, R. H., Burke, B. W., Maher, B. A., \& Gottesman, I. A longitudinal study of the genetics of personality. Journal of Personality and Social Psychology, 1976, 34, 510-518.

Gormly, J., \& Edelberg, W. Validity in personality trait attribution. American Psychologist, 1974, 29, 189-193.

Gormly, J., \& Gormly, A. Approach-avoidance: Potency in psychological research. Bulletin of the Psychonomic Society, 1981, 17, 221-223.

McGowan, J., \& GormLY, J. Validation of personality traits: A multicriteria approach. Journal of Personality and Social Psychology, 1976, 34, 791-795.

Mischel, W. Personality assessment. New York: Wiley, 1968. Rosenthal, D., Wender, P. H., Kety, S., Welner, J., \& Schulsinger, F. The adopted-away offspring of schizophrenics. American Journal of Psychiatry, 1971, 128, 307-311.

(Received for publication October $4,1982$. 